We appreciate the careful differentiation between the various disorders and heartily endorse his final statement.

Paul Howell MD

M. Joanne Douglas MD

Vancouver, B.C.

\section{Absence of a capnograph trace after confirmed tracheal intubation}

To the Editor:

Currently, the most reliable and simple indication of successful tracheal intubation consists of detection of a square-wave end-tidal $\mathrm{CO}_{2}$ trace on a capnograph over three to four successive breaths. ${ }^{1,2}$ However, before the advent of capnography, the best indicaion of successful tracheal intubation was direct observation of the tracheal tube resting between the vocal cords (and including the Ford manoeuvre ${ }^{3}$ ).

We wish to report an incident in which these two indicators appeared to be in conflict. A 22-yr-old, $75 \mathrm{~kg}$ white female was booked to undergo an emergency cystoscopy and possible laparotomy because of abdominal pain of unknown origin. The only abnormality detected on preoperative assessment was that of a complaint of severe pain and nausea. In the operating room at 0200 $\mathrm{hr}$, after application of standard monitors, pre-oxygenation was started at $4 \mathrm{~L} \cdot \mathrm{min}^{-1}$. A square-wave endtidal $\mathrm{CO}_{2}$ trace was shown on the capnograph with each spontaneous breath. Fentanyl $150 \mu \mathrm{g}$ and d-tubocurarine $3 \mathrm{mg}$ were administered $i v$. Two minutes later, a rapid sequence induction was carried out after thiopentone 300 $\mathrm{mg}$ and succinylcholine $120 \mathrm{mg}$. As the patient lost conciousness, cricoid pressure was applied by a nurse (who weighed no more than $60 \mathrm{~kg}$ ). Laryngoscopy was performed, the vocal cords visualized and tracheal intubation accomplished. The tube's cuff was inflated, the circle system attached, the pressure relief valve tightened, and positive pressure ventilation attempted by squeezing the reservoir bag. After six or seven breaths, the usual squarewave capnograph tracing was not seen. The monitor showed only a flat trace $(0 \mathrm{mmHg})$. Haemodynamic and oxygen saturation measurements were all within normal (and expected) ranges. The cuff of the tracheal tube was deflated, the tube removed, and cricoid presure continued. Gentle bag and mask ventilation produced an appropriate trace on the capnograph. After a second dose of succinylcholine, laryngoscopy was repeated and the tube placed under direct vision between the cords. A second attempt at ventilation through the tracheal tube produced the same flat trace.
Because the tube had been observed to rest between the cords, and the patient was haemodynamically stable (including $\mathrm{O}_{2}$ saturation of $100 \%$ ), a decision was made to ignore the capnograph trace. Cricoid pressure was released. Immediately following this, a normal trace appeared on the capnograph screen, with every positive pressure breath. The anaesthetic and operation then proceeded without further incident.

This incident highlights the dilemma of conflicting information from two of the best indicators of tracheal intubation, capnometry and direct visualization. The mechanism of production of the flat trace was thought to be pressure on the tracheal tube, pushing it against the tracheal wall, and producing a ball-valve effect. This is yet another potential problem resulting from cricoid pressure.

Previous reports of failure of capnography after confirmed tracheal intubation inlcude one case of a leak around a $5.0 \mathrm{~mm}$ uncuffed tube in a five-yr-old. ${ }^{4}$ The other report was of a 64-yr-old obese woman with whom there had been difficulty with tracheal intubation. Absence of a $\mathrm{CO}_{2}$ trace was determined to be due to mechanical failure of the capnograph cuvette. ${ }^{5}$

Decision making in anaesthesia often requires rapid analysis of data from various sources, and is more difficult in emergencies and at night. Although current monitors provide life-saving information, anaesthetists must not forget that one of the most important sources is direct observation of the patient.

\section{T.K.K. Tang MD FRCPC}

J.M. Davies MD FRCPC

Department of Anaesthesia

Foothills Hospital and the University of Calgary

Calgary, Alberta T2N 2T9

\section{REFERENCES}

1 Bhavani-Shankar K, Moseley H, Kumar AY, Delph Y. Capnometry and anaesthesia. Can J Anaesth 1992; 39: 617-32.

2 Stehling L. Management of the airway. In: Barash PG, Cullen BF, Stoelting RK (Eds.). Clinical Anesthesia, 2nd ed. Philadelphia: JB Lippincott Company, 1992; 698-9.

3 Ford $R W J$. Confirming tracheal intubation - a simple manoeuvre. Can Anaesth Soc J 1983; 30: 191-3.

4 Markovitz BP, Silverberg $M$, Godinez RI. Unusual cause of an absent capnogram. Anesthesiology 1989; 79: 992-3.

5 Dunn SM, Mushlin PS, Lind LJ, Raemer D. Tracheal intubation is not invariably confirmed by capnography. Anesthesiology 1990; 73: 1285-7. 